
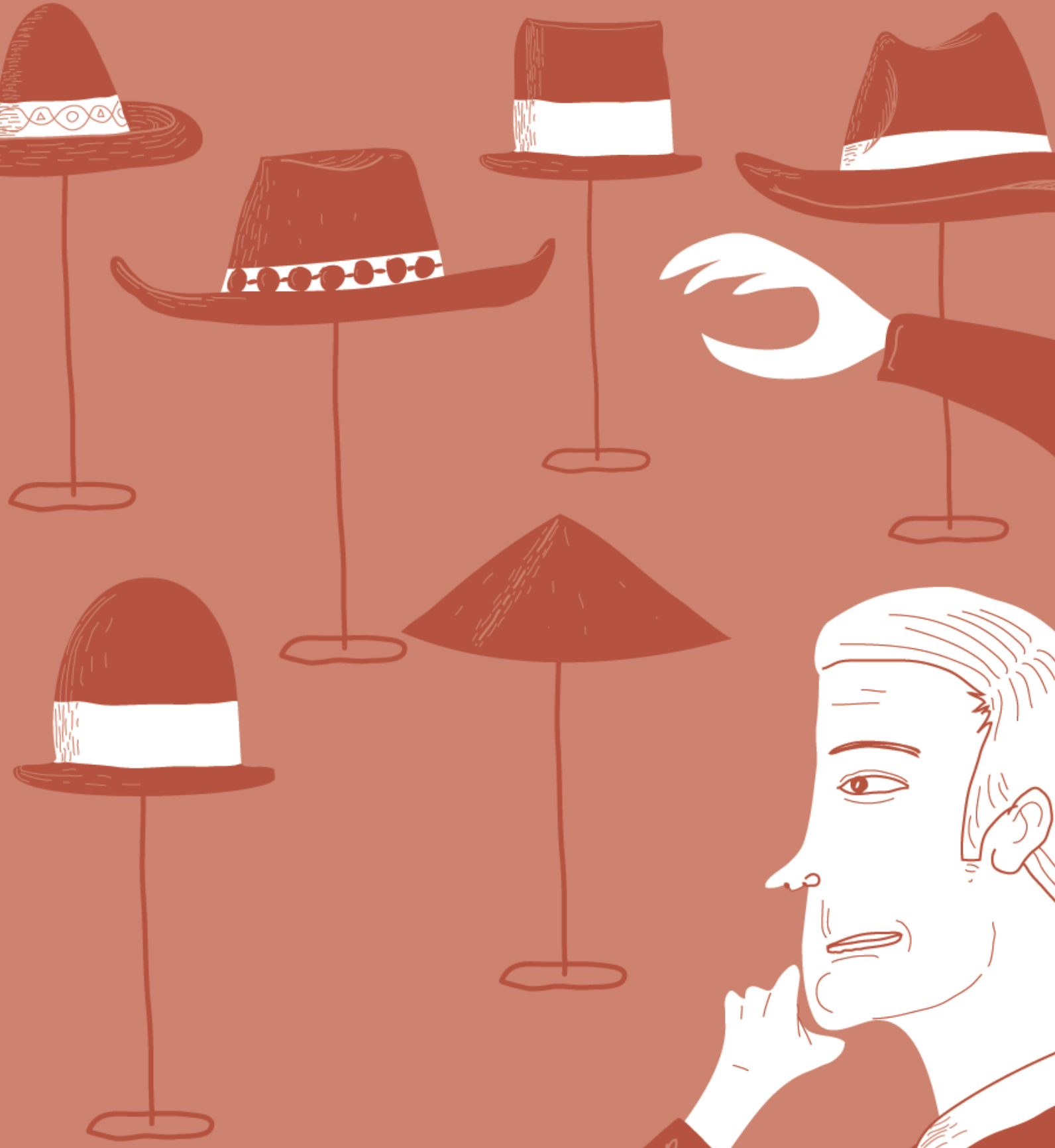


\section{As dimensões locais das Relações Públicas
internacionais: teorias e paradigmas}

Maria Aparecida Ferrari

- Doutora e Mestre em Ciências da Comunicação pela Escola de Comunicações e Artes da Universidade de São Paulo (ECA-USP)

- Professora do curso de graduação em Relações Públicas e do programa de pós-graduação, lato e stricto sensu, da ECA-USP

- Diretora da Faculdade de Jornalismo e Relações Públicas da Universidade Metodista de São Paulo e coordenadora do curso de Relações Públicas da mesma instituição

- Diretora-responsável da revista Estudos de Jornalismo e Relações Públicas, da Universidade Metodista de São Paulo

- Atuou como docente e profissional de Relações Públicas no Chile, entre 1992 e 1997

- É professora-convidada de programas de pós-graduação de universidades latino-americanas

- maferrar@usp.br 


\section{Resumo}

Este artigo aborda o desenvolvimento das Relações Públicas internacionais nas últimas décadas e como sua prática se tornou imprescindível no atual cenário organizacional globalizado. As especificidades da prática das Relações Públicas internacionais exigem uma análise crítica dos sistemas econômico, político, social e cultural do ambiente no qual as organizações transnacionais estão localizadas. As pesquisas desenvolvidas apontam que, mesmo observando os princípios genéricos e as variáveis específicas para entender cada ambiente em particular, é necessário refletir sobre o locus no qual se desenvolverão os programas de Relações Públicas internacionais.

PALAVRAS-CHAVE: RELAÇÕES PÚBLICAS INTERNACIONAIS - ORGANIZAÇÕES TRANSNACIONAIS - globalização • cultura

\section{Abstract}

This article examines the development of International Public Relations during the past decades and how the practice has become an indispensable element in the current global scenario. The specifics of International Public Relations practice require a critique analysis of the economic, political, social and cultural environments where transnational organizations operate. Research shows that even while generic practices and specific variables are used for understanding each specific environment, a reflection on the locus where International Public Relations will be practiced is required.

KEYWORDS: INTERNATIONAL PUBLIC RELATIONS - TRANSNATIONAL ORGANIZATIONS • GLOBALIZATION • CULTURE

\section{Resumen}

Este artículo trata del desarrollo de las relaciones públicas internacionales en las últimas décadas y cómo su práctica se ha vuelto imprescindible en el actual escenario organizacional globalizado. Las especificidades de la práctica de las relaciones públicas internacionales exigen un análisis crítico de los sistemas económico, político, social y cultural del entorno en el cual las organizaciones transnacionales están ubicadas. Las investigaciones desarrolladas señalan que, incluso observando los principios genéricos y las variables específicas para entender cada entorno en particular, es necesario reflexionar sobre el locus en el cual serán desarrollados los programas de relaciones públicas internacionales.

PALABRAS CLAVE: RELACIONES PÚBLICAS INTERNACIONALES • ORGANIZACIONES TRANSNACIONALES

- GLOBALIZACIÓN • CULTURA 
$\mathrm{E}$ mbora a literatura especializada e as pesquisas sobre Relações Públicas internacionais sejam ainda bastante raras no Brasil, o exercício dessa atividade tem se tornado cada vez mais comum nas empresas e organizações nacionais que, em razão da inexistência de um corpo teórico sobre o tema, acabam tendo que se orientar pelo bom senso e pela observação do que se pratica em outros países ou regiões. No campo acadêmico, a bibliografia é, quase em sua totalidade, de origem norte-americana ou européia, o que acaba nos tornando reféns de obras e pesquisas estrangeiras que quase nunca são adequadas ao contexto brasileiro.

A presença de organizações multinacionais e transnacionais ${ }^{1}$ no País e o despertar das nacionais para a utilização das Relações Públicas internacionais, fenômeno irreversível, decorrente da globalização, está a exigir um modelo próprio de gestão da comunicação que ofereça indicadores de análise e de resolução de problemas.

Acreditamos que o estudo do impacto das variáveis ambientais na prática das Relações Públicas possibilita-nos melhorar nossa habilidade de criar estratégias, técnicas e táticas no contexto organizacional e, ao mesmo tempo, avançar em busca de bases científicas que respaldem a atuação dos profissionais que se dedicam ao exercício das Relações Públicas internacionais.

Como contribuição para esta reflexão, é importante destacar a permanente pressão à qual as Relações Públicas têm sido submetidas diante de cenários extremamente vulneráveis em todas as partes do mundo. Neste sentido, a contribuição de James E. Grunig e sua equipe de pesquisadores, ao longo das últimas três décadas, tem sido notável, principalmente pela base empírica e metodológica que o grupo imprimiu aos seus estudos. Uma das preocupações de Grunig está relacionada com o papel das Relações Públicas no âmbito dos negócios e em definir as contribuições da atividade para a efetividade organizacional e societal.

1 Neste texto, usamos o termo "organizações transnacionais" em sua dimensão genérica, para nos referirmos às empresas com fins lucrativos, que operam em mais de um país. Segundo Dicken (1998, p. 177), "uma empresa transnacional é aquela que tem o poder de co-ordenar e controlar operações em mais de um país, mesmo que ela não tenha o controle acionário total nas distintas localidades onde se encontra". Para o autor, esse tipo de organização é a que mais se beneficia do fenômeno da globalização devido à desregulamentação econômica e da privatização das empresas estatais. 
Para Grunig (2003), o momento atual requer reflexão, uma vez que as Relações Públicas passam por cinco tendências, a saber: a) Relações Públicas é uma profissão que possui um corpo de conhecimentos próprio; b) é uma função estratégica e não mais uma função técnica; c) é praticada por profissionais que se desempenham como conselheiros estratégicos e estão cada vez menos preocupados com os instrumentos midiáticos; d) é praticada, cada vez mais, em um cenário de diversidade cultural; e) é cada vez mais global e não está mais confinada às fronteiras locais.

\section{Novo enfoque das Relações Públicas: o equilíbrio entre as partes}

Ao recopilar as definições de Relações Públicas, encontramos um estreito vínculo com a área da Administração de Empresas. Em 1952, Cutlip e Center, em Effective Public Relations, já consideravam as Relações Públicas como uma função gerencial, o que foi retomado, quase 50 anos mais tarde, por Vercic e J. Grunig (2000) quando afirmaram que a teoria dessa atividade teve sua origem na área da administração estratégica e da Economia.

Essa visão administrativa é complementada pela análise de White (1997, p. 159) quando postula que "Relações Públicas é a prática da Administração e uma disciplina de negócios e que, de certa maneira, isso ocorre porque ela é também uma prática moral". O argumento do autor se baseia na premissa de que o profissional de Relações Públicas, ao buscar a efetividade organizacional, poderá servir a interesses que envolvam seu posicionamento moral.

No Brasil, Andrade (1962) e Wey (1983) também relatam que, durante a primeira fase da prática das Relações Públicas, seu estudo estava relacionado à área da Administração (governamental e privada) e que, nesse período, ainda era difusa a relação da atividade com outras áreas da Comunicação, como a Publicidade e Propaganda.

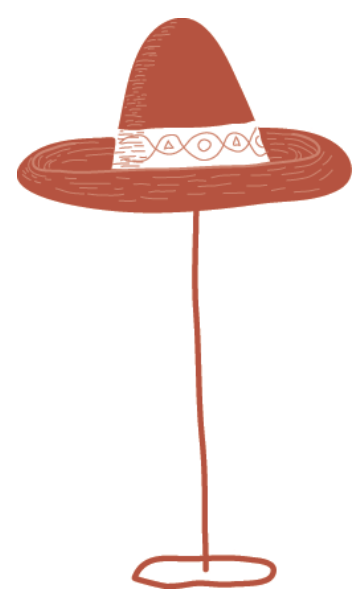

Andrade (1962, p. 45) ressalta que "outro aspecto, não menos importante, é o que observa tratar-se de uma atividade ligada à alta administração de uma empresa, seja ela pública ou privada", mostrando a relação administrativa e estratégica entre os profissionais de Relações Públicas e a liderança responsável pela tomada de decisões.

Sem entrar no mérito do conteúdo das definições de Relações Públicas que foram surgindo ao longo do tempo - de autoria tanto de entidades da categoria como de pesquisadores e estudiosos da profissão -, podemos afirmar, tranqüilamente, que hoje existe um consenso em relação ao seu conceito global, cuja aceitação é unânime pela comunidade de especialistas de Comunicação, principalmente em relação a sua função básica de administradora de relacionamentos. 
França e Ferrari (2003), como a maioria dos autores atuais, procuraram incorporar esse consenso à sua definição, ao afirmar que Relações Públicas é a atividade responsável por "administrar os relacionamentos de uma organização com seus públicos, com o objetivo de manter um diálogo duradouro e eficaz, que permita a possibilidade de simetria entre ambos os protagonistas de uma determinada ação".

Assim, o exercício das Relações Públicas pressupõe, como sua função básica, o planejamento e a gestão dos assuntos públicos e das políticas corporativas permanentes dos relacionamentos organizacionais com seus públicos estratégicos.

Faz parte dessa função estabelecer, desenvolver e manter, de forma planejada, ligações, relacionamentos diretos, gerais ou especializados, entre pessoas, organizações, públicas e privadas, entre públicos da organização e a sociedade, de forma a traduzir esses relacionamentos em benefícios para as partes e a contribuir para a efetividade organizacional.

Esta contribuição pode e precisa ser traduzida em resultados mensuráveis no que diz respeito aos negócios das organizações, o que, segundo pesquisas realizadas por Grunig (1992), torna-se mais fácil na medida em que o comunicador estiver mais próximo da alta administração, porque lhe possibilita ajudar na definição dos objetivos e no desenvolvimento de planos direcionados a seus públicos estratégicos.

Vista por este enfoque, a atividade de Relações Públicas tem duas funções básicas pelas quais atua de forma simultânea e complementar, a saber: a função comunicacional e a função estratégica/gerencial. Se, por um lado, o processo de relacionamento da organização com os públicos estratégicos é fundamental para a criação de um conceito positivo e duradouro na opinião e atitude e no comportamento das pessoas, por outro, o resultado dessa relação pode e deve, como já vimos, agregar valores para ambos os protagonistas: públicos e organização.

Segundo Grunig (2003), as organizações são eficazes quando definem e alcançam objetivos importantes para ela e para seus públicos estratégicos. Neste sentido, as Relações Públicas podem contribuir com resultados mensuráveis enquanto gerenciam a construção de relacionamentos com os públicos que afetam ou são afetados pelas ações organizacionais. Tal relacionamento está baseado no vínculo e no comprometimento com que ambos, organização e públicos, compactuam diante de uma situação de escolhas múltiplas ou de impasse.

Necessário se torna, para tanto, o ordenamento e a administração da inter-relação organização/públicos e públicos/organização, tanto para a sua classificação, quanto para a criação e elaboração de políticas e mensagens adequadas a cada um deles, de acordo com seus interesses e expectativas. 


\section{Relações Públicas internacionais: desvendando sua natureza}

Para compreender o mundo em que hoje vivemos é preciso entender como o fenômeno da globalização influiu e continua influenciando nações, organizações, ambientes de trabalho e família, para citarmos apenas algumas das múltiplas dimensões da vida humana.

Por um lado, a globalização é vista como um fenômeno econômico e social que implica num avanço para a obtenção de um maior grau de integração e interdependência entre as economias dos distintos países e de intensificação das relações sociais em escala mundial. Por outro lado, é analisada como um processo civilizatório, de transformação política, econômica e cultural, em escala planetária (ORTIZ,1999).

Analisada, não importa sob qual dos dois enfoques, o fato é que a globalização alterou a dinâmica das organizações, sejam elas locais, nacionais, multinacionais ou transnacionais, resultando em um mundo mais interconectado e com novas práticas comerciais decorrentes, principalmente, da abertura dos mercados. Hoje, o que ocorre, por exemplo, numa pequena localidade não escapa à influência de fatores relacionados com a economia mundial e com os mercados de bens operados em regiões geograficamente remotas (GIDDENS, 2003).

Também a Comunicação - e, por extensão, Relações Públicas - não escapou ao fenômeno da globalização. Baseadas na prática da Comunicação nos diferentes contextos políticos, econômicos, sociais e culturais, as Relações Públicas definem estratégias específicas para cada país ou região, sem perder de vista os fatores intervenientes da globalização, o que nos permite considerá-las, em sua dimensão internacional, como uma especialidade das Relações Públicas, área maior do conhecimento.

Vários autores norte-americanos, a partir da década de 1990, iniciaram um debate sobre as definições das Relações Públicas internacionais. Anderson (1989) cunhou os termos "internacional" e "global", definindo as Relações Públicas internacionais como a prática de programas de comunicação distintos em vários mercados, com ações especialmente estruturadas para atender cada um deles. As Relações Públicas globais utilizam um programa global em dois ou mais mercados, reconhecendo as similaridades entre os consumidores e públicos e fazendo adaptações para atender as diferenças regionais, levando em consideração o alcance geográfico e a flexibilidade de tomada de decisões.

Para Wilcox, Ault e Agge (1995, p. 414), as Relações Públicas internacionais "compreendem um esforço planejado e organizado de uma companhia, instituição ou governo para estabelecer relações que visem benefícios mútuos com públicos de outras nações”.

Black (1996) apresenta uma visão mais abrangente, definindo as Relações Públicas glo- 
bais como o entendimento mútuo e que buscam suplantar as divergências geográficas, culturais e lingüísticas.

Mais recentemente, Wakefield (2001) descreveu as Relações Públicas internacionais como um processo para estabelecer e manter relacionamentos com públicos em vários países com o objetivo de minimizar ameaças potenciais para as organizações. Para o autor, trata-se de uma extensão da área maior que é Relações Públicas.

Vercic $(1996,2000,2003)$ também se dedicou ao tema ao aplicar os princípios genéricos para analisar as práticas de Relações Públicas na Eslovênia. Juntamente com Wakefield (2001), afirma que atualmente as Relações Públicas internacionais são praticadas de duas formas antagônicas. Na primeira, diretrizes de Relações Públicas locais são aplicadas nos demais países sem nenhuma (ou quase nenhuma) adaptação às necessidades do país estrangeiro. Já na segunda, os programas de Relações Públicas internacionais são totalmente desvinculados das práticas do país de origem.

\section{Relações Públicas no cenário das organizações transnacionais: princípios genéricos e aplicações específicas}

Baseado no projeto The IABC Excellence Study 2, Vercic, L. Grunig e J. Grunig (1996) identificaram características de programas de "Relações Públicas excelentes"3, defendendo a idéia de que as características eram genéricas e que poderiam ser aplicadas globalmente e propuseram dez princípios genéricos:

1. Envolvimento de Relações Públicas na administração estratégica da organização;

2. A atividade de Relações Públicas deve ser reconhecida pela alta administração e o profissional deve ter um relacionamento direto com a presidência da organização;

3. Relações Públicas é uma função que integra a Comunicação Interna e Externa;

4. Relações Públicas é uma função gerencial, separada de outras funções existentes na organização;

2 The IABC Excellence Study: em 1984, esse projeto foi financiado pela International Association of Business Communicators (IABC) Foundation, atualmente chamada de The IABC Research Foundation. Tinha como premissas responder as perguntas: "Como, por que, e quanto a comunicação contribui para alcançar os objetivos organizacionais?" E envolveu 321 organizações nos Estados Unidos, Canadá e Grã-Bretanha. O Excellence Study possibilitou a construção de uma teoria para provar como as Relações Públicas colaboram para a eficácia organizacional.

3 Relações Públicas excelentes é um estado ideal no qual comunicadores com amplos conhecimentos da área assessoram os executivos das organizações em todas as suas estratégias, procurando manter relações simétricas por meio da administração da comunicação com seus públicos-alvo, dos quais depende a sobrevivência e o crescimento organizacional". (DOZIER; GRUNIG, J. e GRUNIG, L., 1995, p. ix) 
5. Relações Públicas é uma função a ser praticada por um administrador da Comunicação e não por um técnico;

6. O modelo simétrico de duas mãos deve ser utilizado para a prática da atividade;

7. O modelo simétrico de duas mãos é fundamental para a Comunicação Interna;

8. A formação continuada e específica na área é fundamental para o desempenho do profissional de Relações Públicas;

9. A diversidade deve estar presente em todos os papéis desempenhados pelos profissionais de Comunicação;

10. O contexto organizacional participativo é favorável para a comunicação excelente.

Uma vez propostos, os princípios passaram a ser aplicados em diferentes países com o objetivo de se verificar a sua validade. Vercic (1998) e Ferrari (2000) aplicaram alguns dos princípios, com resultados positivos, na Eslovênia e em organizações chilenas e brasileiras, respectivamente, e Rhee (2002), com a aplicação de todos os princípios, na Coréia do Sul.

A partir daí, vários estudos foram desenvolvidos ao redor do mundo e Vercic, L. Grunig e J. Grunig (1996) perceberam que a prática em distintos contextos culturais conduzia-os a uma teoria "normativa", ou seja, os princípios passavam a ser chamados de genéricos em decorrência de sua validade em diferentes países e situações organizacionais.

Com a freqüente adoção dos princípios por pesquisadores em várias regiões do mundo, os autores também sugeriram seis "variáveis ambientais" a serem consideradas pelos profissionais na elaboração de estratégias para diferentes países: a) sistema político (ideologia); b) sistema econômico; c) nível do desenvolvimento econômico do país; d) natureza e grau de intensidade do ativismo; e) cultura (incluindo a linguagem); e f) sistema dos meios de comunicação (a natureza do ambiente midiático no país).

Mais tarde, os próprios autores substituíram a denominação "variáveis ambientais" por "princípios genéricos e aplicações específicas". Essa teoria está relacionada com a teoria etnocêntrica, segundo a qual uma organização deve praticar Relações Públicas exatamente da mesma maneira em todos os países (usualmente as diretrizes são definidas pela matriz da organização), ao contrário da teoria policêntrica que defende a prática diferenciada em distintos países, diferenciação essa decorrente do contexto cultural de cada região. 
Fica evidente que as seis variáveis ambientais têm impactos diferentes na prática das Relações Públicas em cada país, mas também ajudam a elaborar estratégias locais para atender as necessidades da comunicação globalizada.

\section{Novas contribuições para o escopo das Relações Públicas internacionais}

Utilizando a conceituação dos princípios genéricos (VERCIC; GRUNIG, L. e GRUNIG, J., 1996), que resultou na primeira teoria para orientar as práticas de Relações Públicas internacionais, Wakefield (1999) conduziu um estudo Delphi ${ }^{4}$ com 23 especialistas em Relações Públicas de 18 países. A escolha da metodologia se deu em razão da intenção de obter informações dos especialistas sobre quão apropriadas eram as variáveis genéricas em seus respectivos países, para determinar se era possível ou não aplicar no contexto cultural de cada país. Também se buscava chegar a um esquema normativo para guiar as práticas futuras das Relações Públicas internacionais e verificar as influências de cada uma das variáveis específicas e de que forma as interferências ocorriam. Com base na identificação das variáveis, o autor propôs uma metodologia para testá-las em cenários internacionais. A utilização do método qualitativo, por meio da técnica Delphi, permitiu ao autor chegar ao que chamou de "fatores de efetividade nas Relações Públicas multinacionais”, que serviram para formar as bases para a prática "classe mundial"5 das Relações Públicas.

Wakefield concluiu que as organizações que praticam Relações Públicas "classe mundial" têm uma filosofia "global" em vez de "ordens centralizadoras" e valorizam o diálogo de "fora para dentro" mais do que a comunicação de "dentro para fora". Além disso, nessas organizações, os profissionais de Relações Públicas de cada unidade se reportam ao executivo sênior no país no qual eles operam e, em seguida, à matriz localizada no país de origem da organização.

O autor sugere também que os profissionais de cada unidade das organizações pratiquem Relações Públicas "classe mundial” todo o tempo e com treinamento apropria-

4 Técnica Delphi é uma ferramenta de pesquisa qualitativa que busca o consenso de opiniões de um grupo de especialistas a respeito de eventos futuros. São três as condições básicas: 0 anonimato dos respondentes, a representação estatística da distribuição dos resultados e o feedback de respostas do grupo para reavaliação nas rodadas subseqüentes. Essa técnica passou a ser disseminada no começo dos anos 1960. Ver: TUROFF, M. e LINSTONE, H. A. The Delphi Method. New York: Addison Wesley Publishing Company, 1975; TERSINE, R.J. e RIGGS, W.E. The Delphi technique: a long-range planning tool. Business Horizons, 19 (2), 51, 56, 1976.

5 "Classe mundial" é uma expressão que foi cunhada por Rosebeth Moss Kanter, em seu livro Classe Mundial (Rio de Janeiro: Campus, 1996). É um jogo de palavras que sugere a necessidade de satisfazer os padrões mais altos existentes para poder participar da competição e, ao mesmo tempo, o crescimento de uma classe social definida por sua habilidade de comandar recursos e operar além das fronteiras e em territórios muito amplos (p. 10). 
do. Segundo os resultados obtidos nos seus estudos, Wakefield elencou cinco estratégias para que as Relações Públicas sejam eficazes em organizações multinacionais e transnacionais:

- Equilíbrio entre o global e o local: o global deve ser o guarda-chuva estratégico mediante o qual os programas são implantados, equilibrando a função global com estratégias específicas que atendam as demandas locais;

- As unidades de Relações Públicas internacionais devem estar integradas com todos os setores ao redor do mundo, disseminando as diretrizes de comunicação entre todos os envolvidos;

- A estrutura horizontal do setor de comunicação deve ser orientada para o trabalho em equipe. É importante a formação de equipes cross-cultural;

- O líder da equipe deve assumir o papel de orientador cultural;

- Deve-se considerar a contratação de agências de comunicação locais.

A análise dos resultados da pesquisa de Wakefield (1999) contribuiu para o estabelecimento de diretrizes para a prática das Relações Públicas internacionais. Ficou confirmado que, mesmo trabalhando com especialistas ao redor do mundo, as bases conceituais de Relações Públicas são muito similares em todos os países, o que nos autoriza a aplicar, internacionalmente, o conceito de Relações Públicas como "administração dos relacionamentos entre uma organização e seus públicos” (FERRARI e FRANÇA, 2003).

Porém, a prática é muito mais complexa do que se levarmos em conta apenas sua dimensão local ou doméstica, o que se deve, sem dúvida, à influência dos diferentes contextos político, econômico, social e cultural. A cultura é provavelmente uma das mais importantes variáveis a serem observadas na prática das Relações Públicas internacionais. O estudo demonstrou que a adaptação às características culturais locais é um dos maiores desafios às organizações transnacionais. Prova disso é a dificuldade do aprendizado do idioma local e da interpretação dos significados das palavras.

Outra variável que merece destaque é o ativismo como fator de influência sobre a prática das Relações Públicas internacionais. Seu grau de influência é determinado por duas outras variáveis, a saber: o sistema político e o nível de desenvolvimento econômico do país.

Neste sentido, merece especial atenção a crescente influência do ativismo transnacional de determinados grupos como Greenpeace, cujas ações têm repercussão em nível mundial. No entanto, os especialistas que participaram do estudo Delphi foram unânimes em reforçar a necessidade de um forte programa local de Relações Públicas capaz de identificar as pressões de ativistas em potencial e de com eles construir sólidas relações. Tais programas poderão transformar o ativismo em oportunidades e não em ameaças para as organizações transnacionais. 
Finalmente, os especialistas identificaram a mídia como o mais importante público de ação local por exercer uma forte influência nos habitantes da comunidade, o que não exclui o alcance da mídia internacional, principalmente depois do advento das tecnologias de comunicação. Sem dúvida, o mais corriqueiro fato local pode, no mesmo instante, se tornar uma questão de Estado mundial.

\section{Considerações finais}

São claras as razões que nos levam a acreditar que as constantes e rápidas transformações pelas quais passa o mundo estão criando mecanismos de sobrevivência cada vez mais complexos para as organizações. As conseqüências de iniciativas localizadas não se restringem mais aos limites das fronteiras geográficas e ganham dimensões globais. Desta forma é fácil compreender porque o "mundo se tornou pequeno" e, por conseqüência, os relacionamentos entre pessoas de diferentes partes do planeta vêm ganhando dimensões tão significativas.

No contexto empresarial, o mesmo está acontecendo se observamos que o fim das barreiras comerciais e a urgência de desenvolver habilidades para interagir e trabalhar com instituições de diferentes partes do mundo é uma exigência para o sucesso dos negócios.

$\mathrm{Na}$ academia, uma nova área de estudos cross-cultural management surge para tentar desvendar as dimensões internacionais do comportamento das organizações, visto que os ambientes nos quais elas se inserem e com os quais interagem estão a exigir novos indicadores de comportamento, tanto administrativo quanto comunicacional.

No início deste artigo, apontamos a proximidade da função de Relações Públicas com a área da Administração com o objetivo de mostrar que o processo de comunicação permeia as práticas organizacionais. Neste sentido, as Relações Públicas apóiam as organizações para lidar com questões como meio ambiente, diretrizes organizacionais, responsabilidade social e competências básicas necessárias ao comprimento de sua visão de negócio. A Administração torna-se, portanto, relevante para as Relações Públicas na medida em que a prática da atividade tem como objetivo a melhoria da sustentabilidade das organizações mediante o incremento dos relacionamentos com seus públicos estratégicos. Esta aproximação se dá por meio do desenvolvimento de ações de comunicação estruturadas e dirigidas às necessidades específicas de cada um dos públicos classificados.

Assim, uma vez que a prática das Relações Públicas internacionais tem se intensificado devido ao fenômeno da globalização, cabe aos profissionais de comunicação conhecer e identificar os cenários peculiares de cada país para, neles, gerir a comunicação, tanto em seus aspectos relacionais quanto administrativos. 
Neste contexto entram os princípios genéricos e as variáveis ambientais apresentadas por Vercic, L. Grunig e J. Grunig, que os relacionistas poderão utilizar para conseguir o que Wakefield chamou de "fatores de efetividade nas Relações Públicas multinacionais".

Diante do atual contexto mundial, as Relações Públicas têm, como uma de suas funções básicas, a busca do equilíbrio de objetivos, tentando "harmonizar" as demandas do ambiente externo com os interesses da organização e, vice-versa, os interesses da organização com as demandas do ambiente externo.

Finalmente, vale ressaltar que o profissional de Relações Públicas deve garantir as compatibilidades culturais no ambiente dos negócios, agindo como o "integrador cultural”, sempre sensível às questões locais e às idiossincrasias de seus públicos estratégicos.

O atual ambiente globalizado é altamente vulnerável e o comprometimento com o paradigma da interatividade é, portanto, um imperativo para o equilíbrio sócio-ambiental. Se, por um lado, os conflitos tendem a se intensificar, por outro, a interatividade facilita a construção de relacionamentos sólidos, éticos e eficazes para todos os envolvidos, não importa o limite geográfico. Esta é, em nossa visão, a abordagem que garante o caráter local à prática das Relações Públicas internacionais.

\section{Bibliografia}

ANDRADE, C. T. S. Para entender relações públicas. 4. ed. São Paulo: Loyola, 1993.

CUTLIP, Scott; CENTER, A. e BROOM, G.. Effective public relations. New Jersey: Prentice-Hall, 1952.

DICKEN, P.. Global shift: transforming the world economy. 3. ed. London: Paul Chapman, 1998.

DOZIER, D. M.; GRUNIG, L. e GRUNIG, J.. Manager's guide to excellence in public relations and communication managenent. Mahwaj: New Jersey, 1995.

FERRARI, Maria A.. A influência dos valores organizacionais na determinação da prática e do papel dos profissionais de relações públicas: estudo comparativo entre organizações do Brasil e do Chile. Tese (Doutorado em Comunicação) - Escola de Comunicações e Artes. São Paulo: Universidade de São Paulo, 2000.

GUIDDENS, A.. O mundo em descontrole. Rio de Janeiro: Record, 2003.

GRUNIG, J. E. (org.). Excellence public relations and communication management. Hillsdale, NJ: Lawrence Erlbaum Associates, 1992.

GRUNIG, J. E.. A função das relações públicas na administração e sua contribuição para a efetividade organizacional. In: Revista Comunicação \& Sociedade. Universidade Metodista de São Paulo, São Bernardo do Campo, ano 24, no. 39, 2003, p. 67-92. 
KANTER, Rosebeth M.. Classe mundial. Rio de Janeiro: Campus, 1996.

MOLLEDA, J. C. e LASKIN, A.. Global, international, comparative and regional public relations knowledge from 1990 to 2005: a quantitative content analysis of academic and trade publications. Pesquisa publicada pelo Institute for Public Relations, Gainsville, EUA, 2005.

MOSS, D.; MACMANUS, T. e VERCIC, D.. Public relations research: an international perspective. London: International Thomson Business Press, 1997.

ORTIZ, Renato. Mundialização, cultura e política. In: DOWBOR, Ladislau; IANNI, Octávio e RESENDE, Paulo-Edgar (orgs.). Desafios da globalização. Petrópolis: Vozes, 1999. p. 273.

RHEE, Y. Culture and dimensions of communication in public relations: an exploratory study of south korean practitioners. Artigo apresentado no ICA, Seul, Coréia do Sul, julho de 2002.

VERCIC, D. e GRUNIG, J. E.. The origins of public relations theory in economics and strategic management. In: MOSS, D.; VERCIC, D. e WARNABY, G. (orgs.). International public research. London: Routledge, 2000. p. 9-58.

VERCIC, D.; GRUNIG, L. A. e GRUNIG, J. E.. Global and specific principles of public relations: evidence from Slovenia. In: CULBERTSON, H. M. e CHEN, N. (orgs.). International public relations: a comparative analysis. Mahwah, NJ: Lawrence Erlbaum Associates, 1996, p. 31-65.

WAKEFIELD, Robert I.. International public relations: a theoretical approach to excellence base on a worldwide Delphi study. Tese de Doutorado - College Park. University of Maryland, EUA, 1999.

WEY, Hebe. O processo de relações públicas. São Paulo: Summus, 1983.

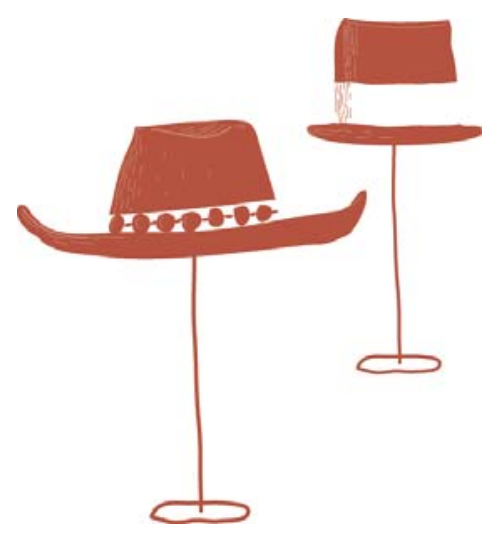

